\title{
Heat Deflection Temperature (HDT) Properties of Polypropylene Composite Reinforced Cellulose Microfibrils of Oil Palm Empty Fruit Bunch and Frond
}

\author{
Wida B. Kusumaningrum and Sasa Sofyan Munawar
}

\begin{abstract}
Polypropylene composites reinforcing with natural fiber is potentially applied for automotive particularly on interior part design. Those kind of composites were contributed on renewable material, rapid rate biodegradation, and low cost of production compared to synthetic fiber. Furthermore, the mechanical properties including strenghtness, young modulus, and thermal stability have revealed good performance than glass fiber. Fiber which were fibrillated and have high aspect ratio that coresspond to diameter and lenght ratio of the fiber were noticed as enhancement factor for mechanical properties. Fiber fibrillation processing into microfibrillated cellulose (MFC) attempts for widening surface area of the fiber that improve polymer matrices compatibility. MFC from empty fruit bunches (EFB) and oil palm frond (FB) fibers were performed as pulp by mechanically and chemically treatments. Chemically treatment was conducted with bleach and unbleach procedure. Polypropylene with fiber was mixed using kneader, and injection for molding process. Manufacturing uses needs appropriate size presition, moderate lead time, and low defect. Heat deflection temperature (HDT) provide information for plastic material on indicating temperature condition effect to material deformation during normal loading. Material of origin, additive or filler size, and molding temperature were directly corelated to the HDT performance. Initial temperature of HDT exhibits different value for different kind of fillers and fiber treatments. PP/EFB composite by mechanical treatment gives high value of HDT compared to the fiber processing by chemical treatment both with bleach and unbleach process. Similar result have been performed in PP/FB composites related to initial temperature. PP/ EFB composite with $30 \%$ of fiber loading represent HDT in $149.4^{\circ} \mathrm{C}$, and for PP/ FB composite with $30 \%$ fiber loading gives $150.7^{\circ} \mathrm{C}$. By the addition of fiber loading could improve the HDT value of the composites.
\end{abstract}

Keywords: oil palm empty fruit bunches, frond, polypropylene composite, HDT.

\section{Introduction}

Over the demand of sustainable and renewable material in several field such as automotive, medical, and food packaging, hence natural based material widely investigated in last decade. Natural fiber utillization for reinforcement material in polymer matrices especially in automotive part besides reduce the synthetic and metal material consumption that costly high but also could reduce total weight of cars which about 30\% (Subyakto et al. 2009). Furthermore, by the natural fiber addition could overcome for green house effect since as an organic material, natural fiber could assist on carbon dioxide cycle (Hari 2012). Mostly in automotive manufacture remain use synthetic fiber and metal as main material. Synthetic fiber commonly used as reinforcement for plastic composites applied on interior part. The advantages of natural fiber related to renewable, biodegradable, good properties, low cost production (i.e. synthetic fiber), low density, non abrasive, relatively active surface, low carbon dioxide emission, and most of all as a green movement material (Zimmermann et al. 2004; Bhatnagar et al. 2005; Kamel 2007; Ashori 2008). Biocomposites is defined as material consisting of natural fiber as reinforcement and polymer as matric. Polymer usually used in automotive manufacture are provided from petroleum derivatives based such as Polypropylene and Polyethylene. Moreover by the addition of natural fiber, directly affect for polymer consumption reduction which better properties indeed. Molding process commonly used for automotive part are compression molding and extrusion followed with injection molding. However, the properties related such as mechanical, chemical, and thermal are disconnected for each molding process (Liu et al. 2007).

In common with wood, natural fibers have composition consist of cellulose, hemicellulose, and lignin. Secondary wall is imbeded by primary wall, in which cellulose mostly located. Cellulose is as crystalline part, while hemicellulose and lignin are amorphous part (Jonoobi et al. 2009). The depiction of composite are expressed in fibers that cellulose act as reinforce and the amorphous part (i.e. hemicellulose, lignin) role as matric. (Subyakto et al. 2009). Crystallinity of the cellulose are required in order to obtain high strength materials, so that some treatement are applied to degrade amorphous part particularly. Crystalline cellulose possesed $150 \mathrm{GPa}$ in elastic modulus, higher than fiber glass (85 $\mathrm{GPa}$ ) and aramid also (65 GPa) (Samir et al. 2004). Cellulose from non wood source could be an options such as flax, rutabaga, sisal, pineapple, coconut fiber, kenaf, and abaca (Bhatnagar et al. 2005) and also from alga, tunicate, and enzymatic isolation (Iwamoto et al. 2007).

Potencial lignocellulosic source especialy from industrial and agricultural or plantation waste is oil palm solid waste such empty fruit bunch (EFB) and palm frond (PF). According to the data oil palm plantation in Indonesia 
reach 8.9 million hectar in 2011. The CPO production upgrading positively affect to increase oil palm solid waste. The potency are predicted 25 million tonne/ year for EFB and PF could achieve 89 million tonne /year. The utillization of EFB have been conducted with some kind of matrices such Polypropylene (PP), Polyvinyl chloride (PVC), Natural rubber, Phenol Formaldehide (PF), and Polyurethane (PU). Chemical modification was carried out in order to enhance compatibilty between fibers and polymer matric (Shinoj et al. 2011). Several researcher reported the uses of EFB for reinforcing agent to PP matric through out physical, chemical, and mechanical treatment (Sharkh et al. 2004; Khalid et al. 2008; Haque et al. 2009; Norul et al. 2013). Fiber composition strongly affected for mechanical properties of the composite (Khalid et al. 2008), similarly the surface modification with chemical treatment resulted strong hydrogen bonding between fibers and matrices (Haque et al. 2009; Norul et al. 2013). Norul et al. (2013), reported good resistance expose from PP/EFB composites including climate resistance and thermal stability under UV lightening.

Heat Deflection Temperature (HDT) is applied as an important parameter for material design. This property is used to decide appropriate processing technology particularly for high temperature manufacturing. HDT were applied to binary polymers and plastic composite for thermal property investigation since along time (Pava et al. 1974; Wong et al. 2003). Polymers having high degree of crystallinity with presence of fillers enhanced for HDT (Wong et al. 2003; Huda et al. 2006). Nano sized particle used for reinforcement or fillers could increase the HDT value even in small amount of fibers addition with well dispersion on matrices. (Thomas et al. 1996; Martins et al. 2009). Some factors that could enhance the HDT value were glass transition temperature, crystallinity, and fibers loading (Huda et al. 2006).

This research were aimed to investigate the HDT value from PP composites reinforced with empty fruit bunch and palm frond fibers. The effect of fibers composition both EFB and PF onto PP also analyzed toward to HDT value.

\section{Experimental Methods}

\section{Materials}

Polypropylene (PP) copolymer impact grade for automotive was used as the matric and Maleic anhydride Polypropylene (MAPP) was used as a coupling agent. Empty fruit bunch (EFB) and Palm frond (PF) were obtained from Subang, West Java. The fibers firstly processed with mechanical and chemical treatment before applied onto polymer matrices.

\section{Mechanical and Chemical Pulp Preparation}

The fibers by mechanical treatment were cuted using drum chipper, ring flaker, and hammer mill to obtain $0.5-1$ $\mathrm{cm}$ of fibers. Further, obtained fibers were immersed in hot water with $100^{\circ} \mathrm{C}$ within 1 hour, ratio between water and fiber was determined at $1: 10$. Subsequently, treated fibers were milled with coarse disc refiner in 2 times, and finer in 5 times of circulation. Mechanical pulp were sieved with Jhonson screen, and kept under freez condition.

Kraft pulping process were carried out as the chemical treatement. $400 \mathrm{OD}$ of cuted fibers were subjected onto $\mathrm{NaOH}(19 \%$ w/w) and $\mathrm{Na} 2 \mathrm{~S}$ (30\% sulfidity) with krafting solution ratio larutan pemasak $5: 1$. Conditioned fibers were pulped using rotary digester under $160-170^{\circ} \mathrm{C}$ within 3.5 hours (lead time in 2 hours and processing time in 1.5 hours). Unbleached pulp were continously washed, refined, and filtrated with Jhonson screen. Whereas, bleached pulp were processed under C-E-H (Chlorinasion-ExtractionHypochlorotation) methods. Chlorinasion step were conducted using $\mathrm{Cl} 2$ with $3.5 \%$ in consistency under $70^{\circ} \mathrm{C}$ in processing temperature. $\mathrm{NaOH}(1.5 \% \quad \mathrm{w} / \mathrm{w})$ were determined for extraction with $10 \%$ in consistency under $70^{\circ} \mathrm{C}$ within 90 minutes. Hypochlorotation were carried out with $\mathrm{NaOCl}(2 \%$ w/v) under $40 \circ \mathrm{C}$ within 240 minutes and $2 \%$ in consistency.

\section{Production of Composites}

Dried pulp were fibrillated using disc mill which have been dispersed in dry condition. PP were mixed with treated fiber (i.e. mehanical, unbleached pulp, bleached pulp) using kneader Daton under $160-170^{\circ} \mathrm{C}$ along $30-90$ minutes of process. The mixed compound were milled with crusher to obtain uniform particle size and assist for feeding process. Then, were molded using injection molding (capacity 70 tonne) under injection condition at 230,220 , and $210^{\circ} \mathrm{C}$ respectively from feeder, and cooling time within 25 seconds. Resulted test piece were kept under vacuum bag to maintain the moisture content.

\section{Heat Deflection Temperature Analysis}

HDV 1 manual DTUL/ Vicat System ATLAS were subjected to analyzed the HDT value for all samples. The analysis based on ASTM D-648 technical test. The samples were placed edgewise with specimen dimension in $127 \mathrm{x}$ $12.7 \times 6.35 \mathrm{~mm}$. Silicon oil GE SF 81-50, AK 1000 were used for heater medium under minimum flash temperature seted at $20^{\circ} \mathrm{C}$ above test temperature. Heating rate were determined in $2^{\circ} \mathrm{C}$ /minutes untill maksimum temperature reached $200^{\circ} \mathrm{C}$. HDT value were noted as the sample undergo on deflection along $0.25 \mathrm{~mm}$ with normal loading.

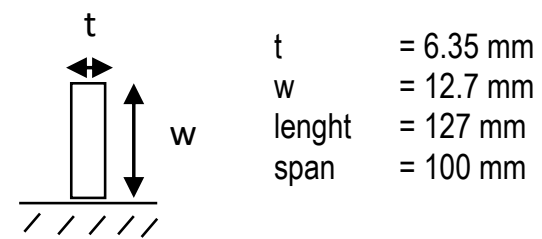

Figure 1. Configuration of HDT sample test. 


\section{Results and Discussion}

\section{Characterization of Composites}

Cellulose content from EFB and PF relatively high. On PF fibers, cellulose content reach $62.34 \%$ and lignin $14.81 \%$ (Syamani et al. 2012). While cellulose content for EFB fibers is known in $41.72 \%$, and other content such hemicellulose in $24.26 \%$, lignin $22.49 \%$, and extractive $11.54 \%$ (Anita et al. 2011). As depict on Fig. 2, that bleached pulp rather bright than unbleached pulp, while mechanical pulp almost like bleached pulp. Delignification and pulping process could enhance for cellulose content about $20.48 \%, 79.45 \%$, and $85.4 \%$ respectively for mechanical pulp, unbleached pulp, and bleahced pulp, simultaneously lignin content reduce and significantly decrease for extractive content of EFB fibers (Kusumaningrum et al. 2012). Beside of cellulose crystallinity, $-\mathrm{OH}$ groups on cellulose gives strong hydrogen bonding with polymer matrices.

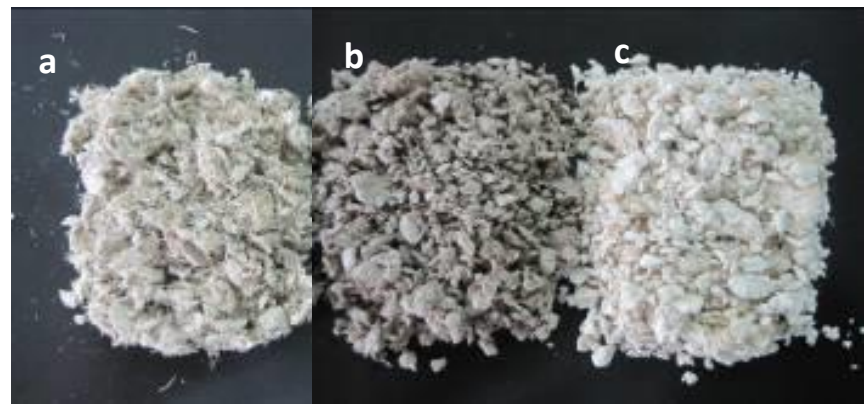

Figure 2. EFB pulp (a) mechanical pulp, (b) unbleached chemical pulp, (c) bleached chemical pulp.
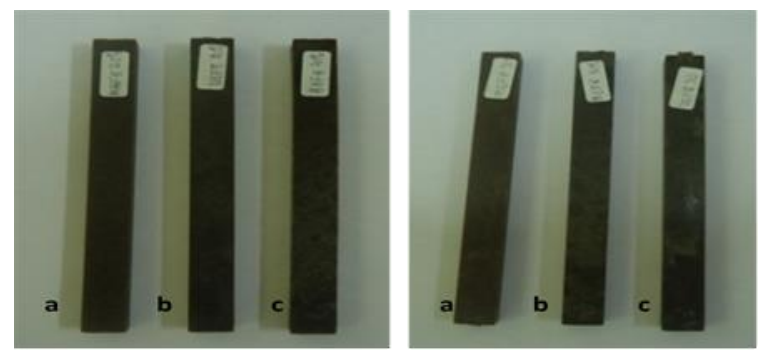

Figure 3. PP/EFB composites (a) mechanical pulp (EFB M), (b) unbleached pulp (EFB UB), (c) bleached pulp (EFB B) (Munawar et al. 2012).

Table 1. Composition of PP/EFB fibers composites and PP/PF fibers composites

\begin{tabular}{ll}
\hline Composites & \multicolumn{1}{c}{ Composition } \\
\hline EFB M 20 & Mechanical EFB Fibers pulp 20\%, PP 75\%, MAPP 5\% \\
EFB M 30 & Mechanical EFB Fibers pulp 30\%, PP 65\%, MAPP 5\% \\
EFB UB 20 & Chemical Unbleached EFB Fibers pulp 20\%, PP 75\%, MAPP 5\% \\
EFB UB 30 & Chemical Unbleached EFB Fibers pulp 30\%, PP 65\%, MAPP 5\% \\
EFB B 20 & Chemical Bleached EFB Fibers pulp 20\%, PP 75\%, MAPP 5\% \\
EFB B 30 & Chemical Bleached EFB Fibers pulp 30\%, PP 65\%, MAPP 5\% \\
& \\
PF M 20 & Mechanical PF Fibers pulp 20\%, PP 75\%, MAPP 5\% \\
PF M 30 & Mechanical PF Fibers pulp 30\%, PP 65\%, MAPP 5\% \\
PF UB 20 & Chemical Unbleached PF Fibers pulp 20\%, PP 75\%, MAPP 5\% \\
PF UB 30 & Chemical Unbleached PF Fibers pulp 30\%, PP 65\%, MAPP 5\% \\
PF B 20 & Chemical Bleached PF Fibers pulp 20\%, PP 75\%, MAPP 5\% \\
PF B 30 & Chemical Bleached PF Fibers pulp 30\%, PP 65\%, MAPP 5\%
\end{tabular}


Table 2. Density of PP/EFB and PP/PF composites.

\begin{tabular}{lc}
\hline Composites & Density $\left(\mathrm{g} / \mathrm{cm}^{3}\right)$ \\
\hline EFB M 20 & 0.942 \\
EFB M 30 & 1.014 \\
EFB UB 20 & 0.977 \\
EFB UB 30 & 0.989 \\
EFB B 20 0.976 \\
EFB B 30 & 0.976 \\
& 1.017 \\
PF M 20 & \\
PF M 30 & 0.947 \\
PF UB 20 & 0.963 \\
PF UB 30 & 0.978 \\
PF B 20 & 1.029 \\
PF B 30 & 0.982 \\
\hline
\end{tabular}

Composites composition between $\mathrm{PP}$ and EFB (PP/EFB) also PP and PF (PP/PF) with various fiber loading are given in Table 1. The opposite properties of PP and fibers which PP in hydrofobic and fibers in hydrofilic require MAPP as a coupling agent in order to improve polymer compatibilities onto fibers. According to previous study (Gopar et al. 2010), optimum MAPP loading in 5\% (w/w) could increased the mechanical properties for PP reinforced with EFB fibers. Over limit MAPP could cause self entlangement that directly decrease the mechanical properties, similarly under limit MAPP could cause MAPP does not well grafted onto PP chain and further lacking of hydrogen bonding.

Composites feature from PP/EFB and PP/PS with mechanical and chemical pulp both unbleached and bleached are not significantly different particularly in colour appearance, as shown in Fig. 3. Some spot appeared in the composites surface, that probably created by greatly different of morphological and physiological properties between PP and fibers, because of gap, shear stress, and quenching during injection process. Table 2 is informed the enhancement of composites density by addition of EFB also PF fibers, even in slightly differences. Composites that reinforced with mechanical pulp gives lower density than chemical. It could be cause higher volume fraction of chemical pulp both unbleached and bleached after milling treatment using disc mill.

\section{Heat Deflection Temperature (HDT) of PP/EFB and PP/PF Composites}

HDT is widely used in material automotive industry and predicted some kind of problems related materials deformation. HDT value for PP/EFB composites are explained in Fig. 4, and Fig. 5 is revealed for PP/PF composites. The addition of EFB also PF fibers on PP matrices could enhance the HDT value. The HDT for pure PP were known at $113.6^{\circ} \mathrm{C}$ (Zhang et al. 2002) testing based on ASTM D 648 with deflection point at $0.25 \mathrm{~mm}$ under $1.82 \mathrm{Mpa}$ loadings. Range about $8.71-32.66^{\circ} \mathrm{C}$ of HDT enhancement were obtain from PP/EFB, whereas 23.6-31.51 ${ }^{\circ} \mathrm{C}$ from PP/PF composites. Presence of fibers could be as nucleating agent in crystalisation process, so that improve strenghtness and thermal stability of composites either PP/EFB and PP/PF and continously affected on HDT value enhancement. Huda et al. (2006) reported some parameters that influence HDT value of polymer, such crystalinity and reinforcement agent or filler. Kenaf fibers reinforcing onto PLA could improve the HDT value reaches 2 times than pure one in $40 \%$ fiber loading, because of spherulite formation during crsytalisation process (Huda et al. 2008).

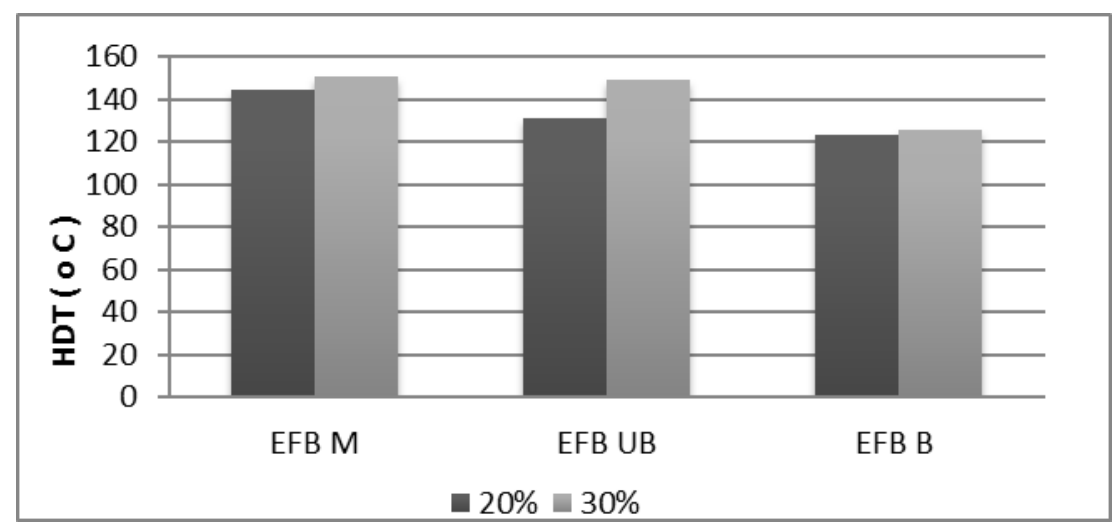

Figure 4. HDT value of PP/EFB composites for each treatment and fiber loading. 


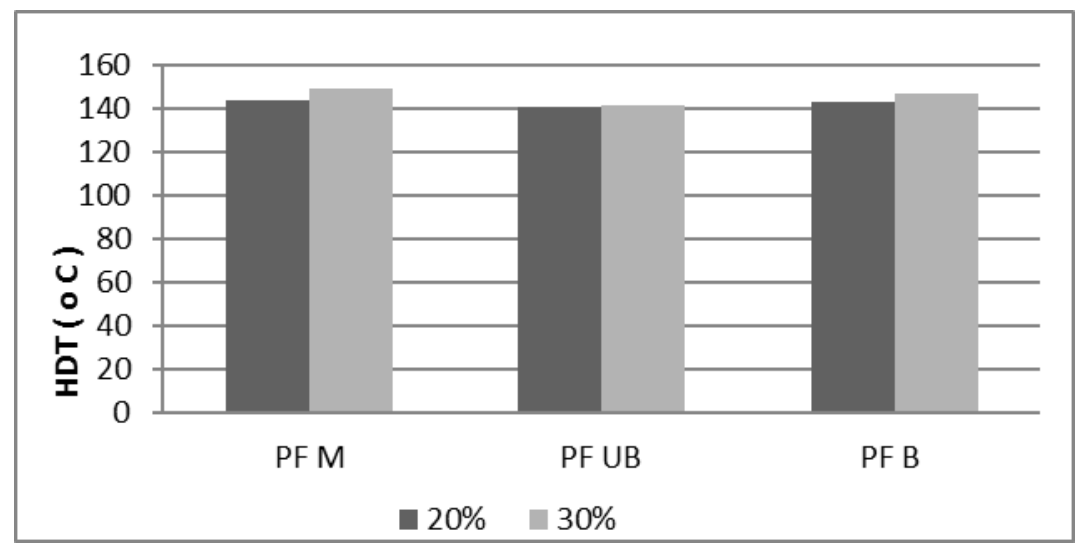

Figure 5. HDT value of PP/PF composites for each treatment and fiber loading.

Fiber loading in composite positively affect on HDT value. HDT value were increased with higher proportion of fiber loading for all kind of pulp, mechanical and chemical both for PP/EFB and PP/PF composites. HDT enhancement by fiber loading addition level result about $3.92 \%, 12.08 \%$, and $1.59 \%$ respectively for mechanical pulp, chemical unbleached pulp, and bleached pulp for PP/EFB composite. While for PP/PF composites about $3.61 \%, 0.5 \%$, and $2.72 \%$ respectively for mechanical pulp, chemical unbleached pulp, and bleached pulp. Fiber loading on CAP composites improved about 13 and 30\% for composition under 15 and $30 \%$ (Mohanty et al. 2004). While, HDT value from PHBV/ wood flour composites increased $24^{\circ} \mathrm{C}$ through $40 \%$ in composition (Singh et al. 2007). As previous report at Huda et al. (2008), trancrystalinity spherulite formation were affected by nucleating agent quantity.

With optimum composition, presence of fibers could improve the strength and tensile modulus that corelated to HDT value. Pulping process of fibers were aimed for delignification in order to improve cellulose content that could refer to crsytallinity form. Beside that, could extensified suface contact with matrices because smaller particle size facilitate for hydrogen bonding that directly affect for mechanical and thermal properties. As reported before in Morreale et al. (2008) that finer particles having greater immobilisation ability on polymer chain. Previous study, Munawar et al. (2012) reported PP/EFB M having greater strength modulus achieved $45.51 \mathrm{MPa}$ than PP/EFB UB and PP/EFB B. The result supported for corelation between strength modulus enhancement and HDT value improvement. As depicted from Figure 4 PP/EFB M have greater HDT value than PP/EFB UB and PP/EFB B. Similalry to PP/EFB, PP/PS M also have higher HDT value than PP/PF UB and PP/PF B. It could be fiber under milling process using disc mill caused lower aspect ratio of chemical pulp both unbleached and bleached due to horizontally cuted. Aspect ratio that correspond to lenght and width ratio of fibers significantly influence for plastic HDT value (Morreale et al. 2008). Some bubbles that were suspected as traped volatile chemical compound and water vapor, gradually create some cavity in composite reinfrocing chemical pulp as shown in Fig. 6. Nunez et al. (2002) adduced that volatile compound during heating process formed microcavity affected debonding between fiber and matrices.
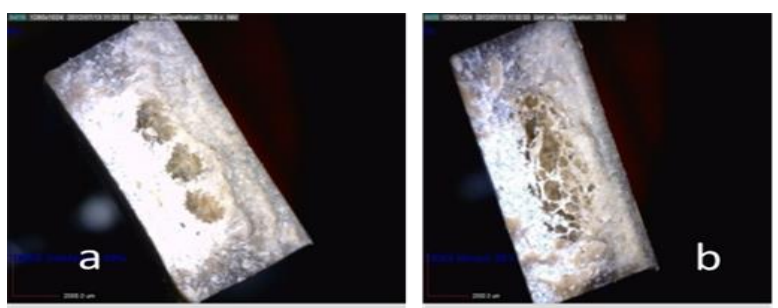

Figure 6. Microcavity on composite PP/EFB by chemical pulping, (a) EFB UB , (b) EFB B.

\section{Conclusions}

Heat deflection temperature of PP/EFB and PP/PF composites significantly improve by the addition of EFB and PF fibers with mechanical and chemical pulping. Composites reinforcing with mechanical pulp original from EFB (PP/EFB M) and PF (PP/PF M) have greater HDT value than reinfrocing with chemical pulp both unblecahed and bleached. Higher fiber loading relatively enhance for HDT value in all fibers treatment, mechanical pulp, chemical unbleached pulp, and chemical bleached pulp.

\section{References}

Abu Sharkh, B.F. and H. Hamid. 2004. Degradation Study of Date Palm Fibre/Polypropylene Composites in Natural and Artificial Weathering: Mecahnical and Thermal analysis. Polymer Degradation and Stability 85: 967-973.

Anita, S.H.; R. Lucky; E. Hermiati; and W. Fatriasari. 2011. Pretreatment of Oil Palm Empty Fruit Bunch (OPEFB) using Microwave Irradiation. In: Proceedings of the $3^{\text {rd }}$ International Symposium of Indonesian Wood 
Research Society. Jogjakarta, Indonesia, pp. 348352.

Ashori, A. 2008. Wood Plastic Composites as Promising Green Composites for Automotive Industries. Bioresource Technolog.: 1-7.

Bhatnagar, A and M. Sain. 2005. Processing of Cellulose Nanofiber Reinforced Composites. Journal of Reinforced Plastic and Composites 24(12): 12591268.

Gopar, M.; Subyakto; K.W. Prasetiyo; and Ismadi. 2010. Karakteristik Biokomposit Plastik Mikrofibril Selulosa Tandan Kosong Kelapa Sawit. In: Proceedings of the $13^{\text {th }}$ MAPEKI. Bali, Indonesia. pp. 86-92.

Hari. R.S. 2012. Teknik Manufaktur Komposit Hijau dan Aplikasinya. Performa 11(1): 9-18.

Haque, Md.M.; M. Hasan; M.S. Islam; and M.E. Ali. 2009. Phsyco-mechanical Properties of Chemically Treated Palm and Coir Fiber Reinforced Polypropylene Composites. Bioresource Technology 100: 4903-4906.

Huda, M.S; L.T. Drzal; A.K. Mohanty; and M. Misra. 2006. Chopped Glass and Recycled Newspaper as Reinforcement Fibers in Injection Molded PLA Composites: A Comparative Study. Composites Science and Technology 66: 1813-1824.

Huda, M.S.; L.T. Drzal; A.K. Mohanty; and M. Misra. 2008. Effect of Fiber Surface Treatments on the Properties of Laminated Biocomposites from PLA and Kenaf Fiber. Composites Science and Technology 68: 424432.

Iwamoto, S.; A.N. Nakagaito; and H. Yano. 2007. Nanofibrillation of Pulp Fibers for the Processing of Transparent Nanocomposites. Applied Physical A. 89: 461-466.

Jonoobi, M.; J. Harun; A. Shakeri; M. Misra; and K. Oksman. 2009. Chemical Composition, Crytallinity, and Thermal Degradation of Bleached and Unbleached Kenaf Bast (Hibiscus cannabinus) Pulp and Nanofibers. Bioresources 4 (2): 626-639.

Kamel, S. 2007. Nanotechnology and Its Applications in Lignocellulosic Composites, a Mini Review. Express Polymer Letters 1(9): 546-575.

Khalid, M.; C.T. Ratnam; T.G. Chuah; S. Ali; Thomas; and S.Y. Choong. 2008. Comparative Study of Polyproylene Composites Reinforced with Oil Palm Empty Fruit Bunch Fiber and Oil Derived Cellulose. Materials and Design 29: 173-178.

Kusumaningrum, W.B.; S.M. Sasa; A. Lilik; K.H. Wawan K.H. 2012. Karakterisasi Kimia Pulp Tandan Kosong Kelapa Sawit. In: Proceedings of $2^{\text {nd }}$ Masyarakat Perkelapasawitan Indonesia (MAKSI). Bogor, Indonesia. pp. 458-463

Liu, W.; L.T. Drzal; A.K. Mohanty; and M. Misra. 2007. Influence of Processing Methods and Fiber Length on Physical Properties of Kenaf Fiber Reinforced Soy Based Biocomposites. Composites Part B 38: 352359
Martins, C.G.; N.M. Larocca; D.R. Paul; and L.A. Pessan. 2009. Nanocomposites Formed from Polypropylene/ EVA Blends. Polymers 50: 1743-1754.

Mohanty, A.K.; A. Wibowo; M. Misra; and L.T. Drzal. 2004. Effect of Process Engineering on the Performance of Natural Fiber Reinforced Cellulose Acetate Biocomposites. Composites Part A 35: 363-370.

Morreale, M.; R. Scaffaro; A. Maio; F.P. La Mantia. 2008. Effect of Adding Wood Flour to the Physical Properties of Biodegradable Polymer. Composites Part A 39: 503-513.

Munawar, S.S.; B. Subiyanto; I. Budiman; L. Astari; and W.B. Kusumaningrum. 2012. Studi tentang Kekuatan Mekanis Komposit Polipropilena-Serat Tandan Kosong Sawit. Have been presented in MAPEKI XV, Makasar, Indonesia, 6 November 2012.

Norul, M.A.; M.T. Paridah; U.M.K. Anwar; M.Y. Mohd Nor; and P.S. H'ng. 2013. Effect of Fiber Treatment on Morphology, Tensile and Thermogravimetric Nanlysis of Oil Palm Empty Fruit Bunches Fibers. Composites Part B 45: 1251-1257.

Nunez, A.J.; M.K. Jose; M.R. Maria; I.A. Mirta; and E.M. Norma. 2002. Thermal and Dynamic Mechanical Characterization of Polypropylene - Woodflour Composites. Polymer Engineering and Science 42(4): 733-742.

Pava, A.; M. Rink; G. Blundo; and F. Danusso. 1974. Characterization of the Thermomechanical Behaviour of Polymers: Non-isothermal Creep Deflection Processes. Polymer 15: 243-247.

Samir M.; F. Alloin; M. Paillet; and A. Dufresne, Tangling. 2004. Effect in Fibrillated Cellulose Reinforced Nanocomposites. Macromoleculs 37: 4313-4316.

Shinoj, S.; R. Visvanathan; S. Panigrahi; and $M$. Kochubabu. 2011. Oil Palm Fiber (OPF) and Its Composites: A Review. Industrial Crops and Products 33: $7-22$.

Singh, S. and A.K. Mohanty. 2007. Wood Fiber Reinforced Bacterial Bioplastic Composites: Fabrication and Performance Evaluation. Composites Science and Technology 67: 1753-1763.

Subyakto; E. Hermiati; D.H.Y. Yanto; Fitria; I. Budiman; Ismadi; N. Masruchin; and B. Subiyanto. 2009. Proses Pembuatan Serat Selulosa Berukuran Nano dari Sisal (Agave sisalana) dan Bambu Betung (Dendrocalamus asper). Berita Selulosa 44(2): 57-65.

Syamani, F.A. and B.K. Wida. 2012. Characteristic of Fibrillated Oil Palm Frond Pulp and Polyvinyl alcohol Composite, Have been presented in the $4^{\text {th }}$ International Symposium of Indonesian Wood Research Society, Makasar, Indonesia, 7-8 November 2012.

Thomas, J.L. and W.M. Groenewoud. 1996. The Infulence of Fibre Length and Concentration on the Properties of Glass Fibre Reinforced Polyropylene: 2. Thermal Properties. Composites Part A, 27A: 555-565. 
Wong, A.C. 2003. Heat Deflection Characteristics of Polypropylene/Polyethylene Binary System. Composites Part B, 34: 199-208.

Zhang, M.; Y. Liu; X. Zhang; J. Gao; F. Huang, Z. Song; G. Wei; and J. Qiao. 2002. The Effect of Elastomeric Nano Particles on the Mechanical Properties and Crystallization Behaviour of Polypropylene. Polymer 43: 5133-5138.
Zimmermann T.; E. Pohler; and T. Geiger. 2004. Cellulose Fibrils for Polymer Reinforcement. Advanced Engineering Materials 6(9): 754-761.

Wida B. Kusumaningrum and Sasa Sofyan Munawar Research Center for Biomaterials LIPI, JI Raya Bogor Km 46 Cibinong Bogor

Email : wida.banar@biomaterial.lipi.go.id 